\title{
Dr. Amanda E. Schwint: enjoy every step of the way and admit "there are always more questions than answers"
}

Received: 27 November 2018; Accepted: 10 December 2018; Published: 12 December 2018.

doi: $10.21037 /$ tro.2018.12.01

View this article at: http://dx.doi.org/10.21037/tro.2018.12.01

\section{Editor's note}

The $18^{\text {th }}$ International Congress on Neutron Capture Therapy was held successfully for the first time in Taipei, Taiwan from October 28 through November 2, 2018. The congress was spread over six days and featured training courses, parallel sessions, plenary talks, invited lectures, and poster viewing and presentations.

This conference was composed of world-renowned multidisciplinary experts from industry and academia, working together on the goals of cancer treatment. Just like the theme "Precision Therapy, Beautiful Tomorrow-We Here, We Care," a number of encouraging findings were presented and constructive discussions were held during the congress. With these ongoing developments, the promise of Boron Neutron Capture Therapy as a standard radiation therapy for cancer is becoming a reality.

At the congress, Dr. Amanda E. Schwint gave three impressive speeches on "Optimization of drug delivery and therapeutic effects based on the knowledge of BNCT radiobiology", "The privilege of working together for BNCT", and "Translational radiobiological BNCT studies for the treatment of head and neck cancer, liver and lung metastases, rheumatoid arthritis and induction of abscopal effect: a bench to bedside approach" (Figure 1).

We are honored to invite Dr. Schwint to share her insights into the current situation of her field, some recent research projects together with the findings and challenges encountered, and her genuine advice and encouragement to young researchers (Figure 2).

\section{Expert's introduction}

Dr. Amanda E. Schwint (Figure 3), is Head of the Radiation Pathology Division of the Department of Radiobiology of the National Atomic Energy Commission (CNEA) of Argentina and Principal Investigator of the National Research Council (CONICET) of Argentina. She is also a member of the Executive Committee and of the Board

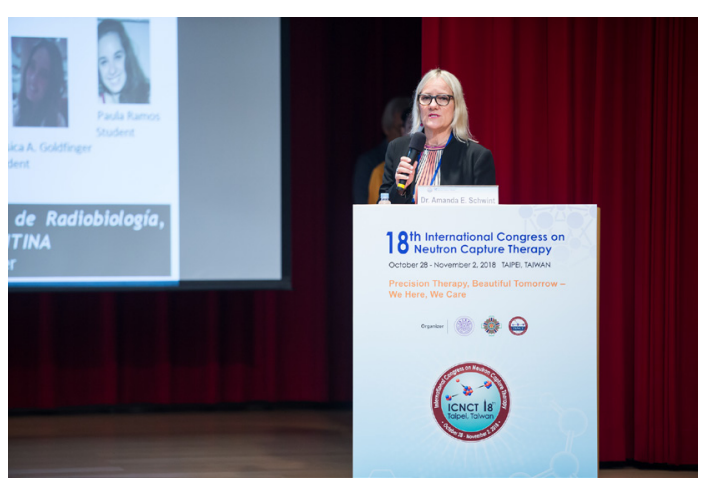

Figure 1 Dr. Schwint presented the Hatanaka award lecture: the privilege of working together for boron neutron capture therapy (BNCT).

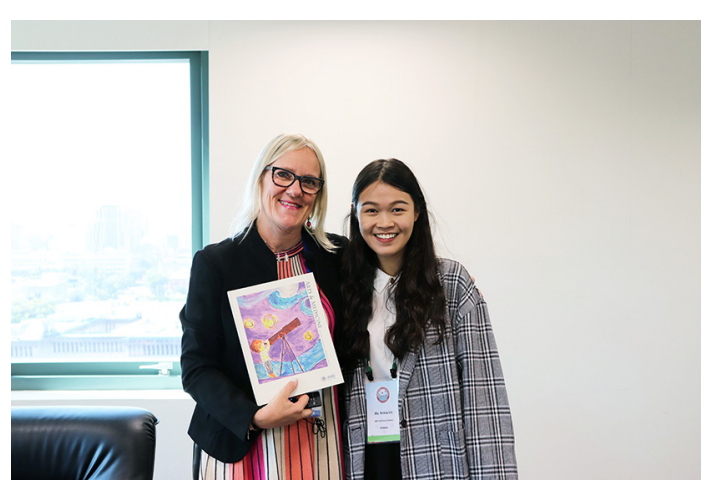

Figure 2 Dr. Schwint and editor from Therapeutic Radiology and Oncology.

of Councilors of the International Society for Neutron Capture Therapy and is Chair of the Technical Committee of Boron Neutron Capture Therapy (BNCT) Radiobiology.

She completed her undergraduate training as a Biologist at the Faculty of Exact and Natural Sciences, University of Buenos Aires (FCEyN, UBA), in 1981 and her PhD at CNEA and FCEyN, UBA, in 1986. She coordinates the interdisciplinary project "Translational Boron Neutron 


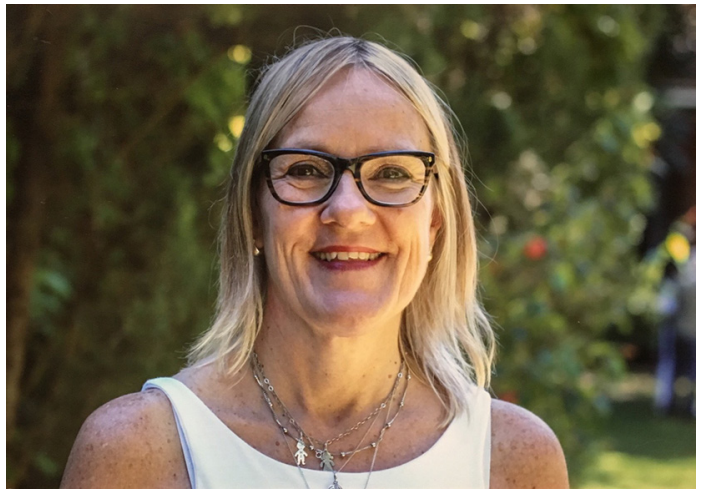

Figure 3 Amanda E. Schwint, PhD, Head, Radiation Pathology Division, Department of Radiobiology, National Atomic Energy Commission (CNEA), Argentina; Principal Investigator, National Research Council (CONICET), Argentina.

Capture Therapy (BNCT) studies for the treatment of head and neck cancer, liver and lung metastases, rheumatoid arthritis and induction of abscopal effect; clinical-veterinary BNCT studies for the treatment of head and neck cancer" in CNEA.

Dr. Schwint is an internationally recognized expert in Radiobiology of BNCT and winner of the 2018 Hatanaka Award. She has published over 70 scientific articles in international peer-reviewed journals and several book chapters and has supervised $6 \mathrm{PhD}$ thesis. She has delivered multiple invited lectures to national and international audiences. She considers that teamwork is pivotal to the progress of Science and makes professional life a pleasure.

\section{Interview (Figure 4)}

TRO: How is the recent progress of BNCT in Argentina?

Dr. Schwint: We have a very interdisciplinary group with different groups of people doing good teamwork on various aspects of BNCT. In that sense, translational research translates into clinical application. For the time being, our clinical trials focus on melanoma. But shortly, we hope to be initiating clinical trials for head and neck cancer.

\section{TRO: Although BNCT is a promising cancer therapy,} there is still plenty of room for improvement. Would you tell us the current challenges in clinical trials of BNCT?

Dr. Schwint: Yes, there is definitely room for improvement. I think the challenges in clinical trials are to identify which tumors and patients would benefit the most from

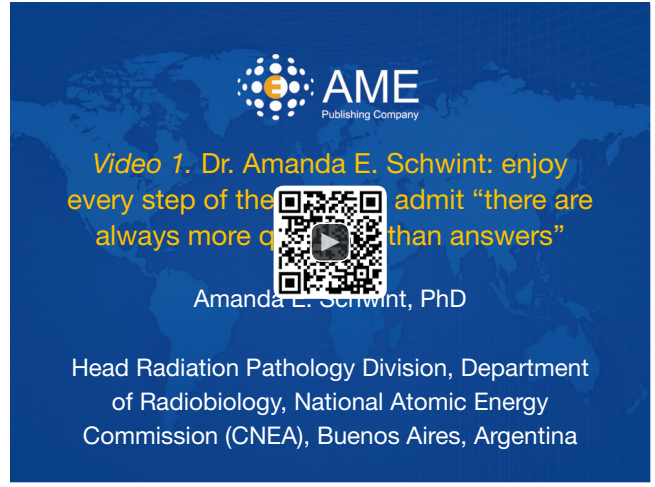

Figure 4 Dr. Amanda E. Schwint: enjoy every step of the way and admit "there are always more questions than answers" (1). Available online: http://www.asvide.com/article/view/28809

BNCT and identify pathologies and cases in which combined treatment would be more efficient and less toxic. So basically, not only do we need to find better boron compounds but also need to improve the boron compounds we currently have and optimize the delivery of the boron compounds that are currently authorized for use in humans.

\section{TRO: In addition to the BNCT research, you also bave} extensive experience with animal models. What leads you to the veterinary studies?

Dr. Schwint: Basically, we go stepwise. We think that in vivo animal models are extremely important to have large numbers that are statistically relevant that give robust scientific data. Then we move on to clinical veterinary studies where we have a smaller amount of animals, of course. The 20 hamsters with tumor we have are all very similar while the clinical scenario involves patients who are all different from one another. So an intermediate step to try out our experimental findings is to move to clinical veterinary studies with patients. We think that is a very significant step before human trials.

\section{TRO: What sort of difficulties have you encountered during animal experiments?}

Dr. Schwint: One difficulty we have is performing noninvasive follow-up. The problem is that, very often, with animal experiments to obtain the data, you have to sacrifice groups of animals. It is therefore too difficult to follow the progression of a disease in a single animal over 
a long period of time. We hope to have a micro positron emission tomography (micro-PET) and micro-computed tomography (micro-CT) equipment next year. In that case, it will be easier to perform follow-up on single groups of animals rather than sacrifice different groups at different times and put together the whole evolution.

TRO: What is the current status of your research project on abscopal effect? And how do you expect it to further develop in the future?

Dr. Schwint: Abscopal effect is extremely interesting. It has been described for standard radiotherapy, but we described it for the first time with BNCT. What we are currently doing is combining BNCT with immunotherapy. In that way, we seem to be obtaining a more robust abscopal effect than with BNCT alone. So we're exploring that avenue of research and also hoping to understand the mechanisms behind abscopal effects.

TRO: What would be your advice to young researchers who would like to develop their expertise in your field?

Dr. Schwint: It would be wonderful for young researchers to join groups that are working on BNCT. I think it is important that you should feel conformable in the group. Perhaps like I did many years ago, you can work with the team first while you are studying, for not very long but 3-4 months before applying for a position, to make sure you feel comfortable in the group. That is the best way of working and producing fruitful scientific results.

\section{Acknowledgments}

We would like to express our sincerest gratitude to Dr. Amanda E. Schwint for sharing her insights and opinions with us.

Funding: None.

doi: $10.21037 /$ tro.2018.12.01

Cite this article as: Lin T. Dr. Amanda E. Schwint: enjoy every step of the way and admit "there are always more questions than answers". Ther Radiol Oncol 2018;2:59.

\section{Footnote}

Provenance and Peer Review: This article was commissioned by the editorial office, Therapeutic Radiology and Oncology for the series "Meet the Professor". The article did not undergo external peer review.

Conflicts of Interest: The author has completed the ICMJE uniform disclosure form (available at http://dx.doi. org/10.21037/tro.2018.12.01). The series "Meet the Professor" was commissioned by the editorial office without any funding or sponsorship. Teresa Lin reports that she is a full-time employee of AME publishing company (publisher of the journal). The author has no other conflicts of interest to declare.

Ethical Statement: The author is accountable for all aspects of the work in ensuring that questions related to the accuracy or integrity of any part of the work are appropriately investigated and resolved.

Open Access Statement: This is an Open Access article distributed in accordance with the Creative Commons Attribution-NonCommercial-NoDerivs 4.0 International License (CC BY-NC-ND 4.0), which permits the noncommercial replication and distribution of the article with the strict proviso that no changes or edits are made and the original work is properly cited (including links to both the formal publication through the relevant DOI and the license). See: https://creativecommons.org/licenses/by-nc-nd/4.0/.

\section{References}

1. Lin T. Dr. Amanda E. Schwint: enjoy every step of the way and admit "there are always more questions than answers". Asvide 2018;5:907. Available online: http://www.asvide. com/article/view/28809

(Science Editor: Teresa Lin, TRO, tro@amegroups.com) 